\title{
Nurse link lecturers' perceptions of the challenges facing student nurses in clinical learning environments: a qualitative study
}

\section{Abstract}

In the United Kingdom student nurses spend approximately half of their education programme in a practical setting commonly referred to as the Clinical Learning Environment (CLE). The significant amount of time student nurses spend in CLEs, combined with reports of negative experiences, indicate that it is important to consider the challenges of learning within this environment. Nurse Link Lecturers spend up to $20 \%$ of their teaching time supporting student nurses in CLEs. Link lecturers' proximity to the CLE means that they are well-placed to articulate the challenges facing student nurses in this context. This paper reports on a study that used interviews and focus groups to collect experienced adult field Link Lecturers' views on the challenges facing student nurses in CLEs. Link Lecturers reported that students often find themselves in polarised positions of either 'fitting in' with the pressures of the environment and thereby potentially gaining 'access to learning' opportunities or 'falling out' and merely 'learning to get through' their placement. Mentors were thought to have a significant influence on student nurses' negotiation of learning. This insight is timely due to the changes in supervisory and assessment arrangements required by the new Nursing and Midwifery Council Standards (NMC 2018). 


\section{Highlights}

- The Clinical Learning Environment may be a challenging environment to learn in (for students) and to teach in (for mentors).

- Mentors are responsible for delivering patient care in addition to supporting student learning.

- In the Clinical Learning Environment, students may find themselves in polarised positions of either 'fitting in' and potentially gaining 'access to learning' opportunities or 'falling out' and merely 'learning to get through'.

- It is timely to reconsider supervisory and assessment arrangements in practice.

Keywords: Supervision, student nurses, clinical learning environments, nurse education

\section{Introduction}

This paper reports nurse lecturers' views of the challenges facing student nurses within the CLE. Most nurse lecturers in the United Kingdom (UK) teach and support student nurses both within University and clinical settings. The clinical activity is termed 'link lecturing'. The Link Lecturer (LL) participants in this study spent $20 \%$ of their normal teaching hours in practice, undertaking this activity, as recommended by the NMC (2008). Because much of their weekly visits to CLEs focus on discussing any difficulties that the students may be encountering, LLs are well positioned to identify and articulate the challenges student nurses encounter in this environment. The views of the LLs in this study are particularly valuable because they spend such a significant 
amount of time in practice; many Schools of Nursing in the UK do not provide such a high level of link lecturing support.

To register as a qualified nurse in the UK student nurses must complete at least a degree level pre-registration nursing programme at a University approved by the Nursing and Midwifery Council (NMC) (NMC, 2018). Student nurses spend approximately half of their programme in clinical practice, with the remainder being spent undertaking related academic activities. Whilst they are in practice, students are required to complete a fulltime working week and experience a full range of shift patterns as a supernumerary learner (NMC, 2018). It is important to consider any challenges that student nurses may encounter when learning within clinical environments because practice forms such a significant component within the curriculum (Henderson, Cooke, Creedy and Walker, 2012). A critical understanding of the current challenges will support clinical and academic staff in operationalizing the new NMC Standards (NMC 2018).

Until Universities embed the new Standards (NMC 2018), through a process of validation, nurse mentors will continue to provide the primary form of support for student nurses within CLEs (NMC, 2008). All Universities must adopt the new Standards by September 2020. Until such time, mentorship requirements remain specified by the NMC within the Standards to support learning and assessment in practice (NMC, 2008). The NMC (2008, p.56) define a mentor as a nurse who 'facilitates learning, and supervises and assesses students in a practice setting'. In the UK, qualified nurses undertake this role, in addition to their clinical responsibilities. 
A recent Royal College of Nursing project $(\mathrm{RCN}, 2015)$ reiterated the importance of good mentorship in enabling the transference of knowledge, whilst simultaneously fostering a learning culture within organisations. However, despite the significant place that mentorship occupies in nurse education and the presence of mandatory standards for mentorship in the UK (NMC, 2008), concerns persist regarding the effectiveness and standard of mentoring in practice $(\mathrm{RCN}, 2015)$. These concerns are clearly articulated in the Willis Commission (Willis, 2012), the National Nursing Research Unit (Robinson, Cornish, Driscoll, Knutton, Corben, and Stevenson, 2012) and the Shape of Caring Report (Willis, 2015) and have informed the new NMC (2018) Standards.

\section{Background}

Despite substantial improvements in nurse education over the last 20 years, literature from the UK suggests that many students still describe their clinical practice as being punctuated by negative experiences (Ion, Smith, Moir and Nimmo 2016; Randle, Stevenson and Grayling, 2007; Thomas, Jack and Jinks 2012; Wilson, 2016). Such negative experiences can have a deleterious effect on student learning, potentially having far reaching effects on their competency development, formation of occupational identify and on their retention in nursing (Newton, Billett and Ockerby, 2009).

Currently, students are required to work with their named mentor(s) for at least $40 \%$ of their practice time (NMC, 2008). Despite the critical function which mentorship occupies, students commonly report that the standard of mentorship is inadequate, with ad hoc mentorship arrangements common place (Thomas et al., 2012). Student nurses frequently report feeling unwelcome, ignored and invisible (Curtis, Bowen. and Reid, 2007). Poor standards of mentorship may be attributed to fact that mentors 
need to manage conflicting demands, balancing requirements to deliver high quality care with the educational tasks associated with their mentorship role (Webb and Shakespeare, 2008).

Mentors commonly report that they lack protected mentorship time, set against high workload pressures (Myall, Levett-Jones and Lathlean, 2008; Veeramah, 2012; Webb \& Shakespeare, 2008). Mentors report feeling inadequately prepared for their role (Andrews, Brewer, Buchan, Denne, Hammond, Hardy, Jacobs, McKenzie and West, 2010) and poorly supported by affiliated Universities (Pollard, Ellis, Stringer and Cockayne, 2007) and the workplace (Nettleton and Bray, 2008). Additionally mentors need to manage the inherent tension created by being both a facilitator and assessor of learning (Bennett and Mcgowan, 2014). Undoubtedly, one of the main challenges that students face in clinical practice is negotiating access to adequate mentorship arrangements. If the mentorship arrangements are inadequate, there is an inherent risk that the student's position within the CLE, as a supernumerary learner, may be eroded because a fundamental function of the mentorship role is to ensure that students are primarily learners and not workers (NMC, 2008).

\section{Methodology}

\subsection{Design}

A qualitative methodological approach was chosen as the best method for gaining an insight into the perceptions of LLs. The study was carried out at a University nursing department in the South of England, which negotiates local clinical placements for student nurses. 


\subsection{Conceptual Framing}

A methodological approach, based on the principles of grounded theory, was selected in order to 'organically' understand and address the data generated on its own terms, and as far as possible, to generate new and unbiased theoretical insights (Corbin and Strauss, 2008). That said, we acknowledge that our interpretation of the data will have inevitably been influenced by lead author's significant professional experience in nurse education and clinical practice, and by her then occupation of a senior position within the Academic Department for Children's Nursing at the School that the participants worked within.

\subsection{Instrument}

The research employed an iterative procedure. Initially, experienced adult field LLs were invited to participate in a semi-structured focus group discussion. Focus groups were chosen as they enabled collective and dynamic exploration of the views of participants. In line with the theoretical sampling techniques of grounded theory, analysis began after the first focus group was conducted (Charmaz, 2014). Analysis of this initial data directed decisions about subsequent sampling and questioning. A second focus group was conducted before a round of semi-structured, one-to-one interviews was held, with selected participants from the focus groups. The one-to-one interviews enabled points of interest from the focus groups to be explored in more detail. The questions in both the focus groups and the interviews concentrated on exploring the perceived challenges faced by student nurses in clinical environments: the questions were varied to enable in-depth consideration of the emerging concepts and categories. Data collection ceased when it was perceived that the major categories demonstrated specificity and were 'dense' in relation to their properties, 
whilst demonstrating variability and integration (Corbin \& Strauss, 2015 p. 141). The focus groups and interviews were audio recorded and transcribed by an external transcription company.

\subsection{Ethical considerations}

This study comprised the initial stage of the lead author's doctoral research in the field of education. The study was reviewed and approved by the research Ethics Subcommittee at the University where the Doctorate was undertaken and by the Research Ethics Panel at the University in which the participants were based. Gatekeeper's permission was also obtained from the participants' Head of School. All invited participants were given verbal and written information about the aims and procedures of the research and they were required to sign written consent forms prior to participation. The lead researcher's erstwhile senior position within the School of Nursing created a risk that participants may have felt compelled to participate and unable to withdraw from the study. It was therefore reiterated, prior to participation, that involvement was entirely voluntary and that participants could withdraw from the study without providing a reason and with no negative consequences. To protect confidentiality participants were advised not to divulge colleagues' names, ward or Trust details during either the focus groups or one-to-one interviews. Participants were also asked to respect the confidentiality of the focus groups. In writing up this research, pseudonyms have been used to ensure anonymity. Only LLs working in adult nursing were invited to participate for two key reasons. Firstly, the lead author's former senior position within the Academic Department for Children's Nursing may have created a sense of coercion among any child LLs invited to participate; secondly we anticipated 
that the inclusion of LLs working in child and mental health fields would have unduly complicated the data set due to the differing clinical contexts and client bases.

\subsection{Participants}

Participants were purposefully selected because they were engaged in adult field link lecturing activities and were perceived to have a comprehensive understanding of the challenges students may face within the CLEs. Fifteen experienced LLs were invited to participate in focus groups, of which $10(67 \%)$ were recruited. Each focus group was attended by five experienced LLs and lasted approximately 60 minutes. All LLs who had participated in either of the focus group discussions were subsequently invited to attend one-to-one interviews. Five LLs were recruited (50\%). Interviews lasted an average of 45 minutes. All focus groups and interviews were held at the University at which the LLs worked during the winter of 2015 . Although the participants were all LLs with similar credentials and worked at the same institution, they did have different professional remits within the University and naturally differing experiences within their link lecturing role.

\subsection{Data Analysis}

Data analysis occurred after each focus group/ interview and followed the analytical steps outlined in Corbin \& Strauss (2008), which included: open coding; memo writing, concept and category generation, underpinned by the process of constant comparison. During analysis, constant comparison was made between the data and the developing concepts and categories until higher levels of abstraction were achieved with the eventual generation of new theory. The iterative design of the research process enabled concepts, categories and theory emerging from analysis of 
the focus group data, to be validated by participants of the interviews. Although the sample size was limited and therefore cannot be assumed representative, insightful data were generated, which may be transferable to other healthcare settings where students are learning in clinical practice. The themes were labelled: 'the importance of mentors in the CLEs'; students 'fitting in' or 'falling out'; 'access to learning' and 'learning to get through'.

\section{Results}

\subsection{The importance of mentors in CLEs}

All the LLs interviewed identified the mentor as a key figure and unequivocally characterised mentors as central to students' opportunities to learn in challenging clinical environments. For example two participants reported that:

"Students rely on the mentors to actually ensure that learning opportunities are maximised" (Focus group 2).

"Mentors help them [the students] to plan their learning ...they actually sit them down and say 'this is what you can do here' and really get them engaged and have a bespoke learning experience" (Navya)

Clare described the mentor role as key to:

"making the students feel like they are a valuable part of the ward, not just 
because they are an extra pair of hands but because they, and the ward, are interested in their learning".

The view that mentors are central to students' potential to learn in CLEs is significant on its own terms, but it is also important because it suggests that poor mentorship can limit students' learning opportunities in CLEs. One LL illustrated this point by rehearsing a typical complaint of students who experienced poor mentoring in CLEs:

"well nobody supported me, I did not learn anything. I was just doing tasks" (Focus group 1).

The lack of support for some students from their mentors, and the subsequent negative impact on their learning opportunities was evident from the data. The LLs agreed that the lack of protected time impinged on mentors' ability to undertake their role fully. One LL commented that mentors need:

"time in every shift to actually sit down and have some reflection with the student on what has happened in that shift and actually put that together so that they can see that that was a learning experience, .....” (Focus group 2).

Without time for reflection there is a risk that the students' learning may not be contextualised and fully exploited, with a possible contraction of potential learning opportunities. Due to time constraints, care provision needs to take priority over learning and teaching in the CLE; the priorities of health services are necessarily 
based on health care provision rather than on the needs of learners in these environments. As a consequence, Navya captured this point by stating:

"They (the students) become very aware, quite quickly that the patients come first and they are a poor second".

A lack of protected time for mentors to devote to supporting students' learning, especially in pressured wards, emerged as a key concern of the LLs.

The participants highlighted the challenges students could face as a result of being placed in 'difficult' CLEs. Ahmed commented:

"Ward $X$ is not good... We know there are staffing issues, we know that a lot of the mentors have changed or gone on long-term sick and we know a new manager is going in. And yet students are still placed there".

When questioned why student nurses are placed in such challenging CLEs, one LL stated:

"We've got this overwhelming sort of big cloud about capacity of placements..." (Focus group 1).

Participants' comments reflected the view that the learning opportunities of students were largely dependent on the quality of mentorship, especially where the CLE created 
additional pressures. However, a lack of placements meant that some students may face the challenge of learning in difficult CLEs, without adequate mentor support.

\subsection{Students 'fitting in' or 'falling out'}

The LLs repeatedly identified the relationship between student and mentor as a potential critical challenge facing students in CLEs. Students "fitting in" or "falling out" with their mentor emerged as a key theme in the data. For example, one LL described one of the key challenges that student nurses face in navigating CLEs as:

"fitting in, getting on with the mentor, being liked by the mentor, pleasing the mentor when they are on duty, working hard" (Focus group 2).

It was evident from participants' comments that if students did not 'fit in', then their access to learning may be compromised. For example, one LL stated that:

"If they don't ever fit in, it's difficult to articulate what they've learnt by the end of a placement, especially if it is a short one" (Heather).

The LLs went on to characterise mentors as 'gatekeepers' of students' learning, either engendering a sense of belonging and consequently enabling student learning or limiting their learning opportunities. For example, Heather stated

"we still have senior people out there acting as a gatekeeper deciding if they (the students) fit in or not". 
She went on to add that students have to please their mentors because as gatekeepers they "can open the learning opportunities or can shut them down".

As well as being gatekeepers of learning opportunities, mentors occupy the role of 'judge' of students' achievements. With evaluation of students in mind, the LLs spoke extensively about the importance to students of completing their Practice Assessment Document and passing their placement.

“There's very few of the BSc students who, I think, think about their learning before getting the [Practice Assessment Document] done and getting the hours done" (Tracey).

The LLs reflected that the Practice Assessment Document represented a critical point of vulnerability for students' relationships with mentors, since without their mentor's positive evaluation they are unable to successfully complete their clinical placement. Putting themselves in the students' position, one LL suggested that this vulnerability can be so significant that it may prevent students from raising clinical concerns:

"If I raise the concern during this placement, can I get my Practice Assessment Document signed? The students prefer to do this statement about poor practice after they finish [their placement]" (Focus group 1).

Clare explained that if students challenge practice, they may compromise their position in the team: 
"So, again even though that area might have a poor culture, everyone is signed up to the culture. But if a student comes in and challenges that, then they don't fit in".

This was seen as significant, with another LL suggesting that a student's challenge might mean:

"the end sometimes of that relationship [with their mentor] and the student's learning" (Focus group 2).

The learning opportunities of students who 'fall out' with their mentor appear significantly diminished, especially if students end up isolated, unsupported or having to complete the placement in an outright hostile CLE. The LLs indicated that students who have previously worked as a Health Care Assistant (HCA) may revert back to this previous role in order to negotiate the challenges associated with the CLE. One LL commented:

"You [meaning the student] put your head down for four, six, twelve weeks and actually adopt that healthcare assistant role and become invisible so that you are seen there as a hard worker" (Focus group 2).

Taking on the role of a HCA may provide a way for students to cope with difficulties within the CLE, and for potentially negotiating a positive relationship with their mentor. However, Heather explained that this strategy may have negative consequences for students' learning: 
"if they can't fit in they just resort to being a HCA..... and the staff view them as great, but actually, by the time they get to be a third year, they are a failing student".

\section{3 'Access to learning' and 'learning to get through'}

Another key theme that emerged from LLs comments concerned students' access to learning opportunities. Again, this was reported as being bound up in the students' relationships with their mentors:

"If students have what they call a very good mentor, they will say that the mentor is going to provide patient care and wherever the mentor goes, they will bring you, the student, along with them and therefore they are learning at the same time (Focus group 1).

Participants spoke of a corresponding danger that isolation from mentors may limit students' access to learning opportunities. Ahmed suggested that in cases where students' access to their mentor is restricted, they may seek out learning opportunities through other relationships:

"I think students find ways of learning if they want to... and if they don't get what they feel they need from their named mentor then they may latch on to somebody else " 
The LLs expressed a deep concern that restricted access to their mentor may lead students to form alternative learning relationships with HCAs. This was considered problematic by the LLs because HCAs are not qualified to support students' professional development and socialisation. For example, one LL stated:

"My worry is that is that the HCAs are socialising them [student nurses] into a different role" (Focus group 2).

"You can really see people who have had consistently difficult placements when they get to their third year and they haven't got the skills. And they haven't got the whole professional attitude ... we blame the student for that but actually that has been our fault..." (Focus group 2).

In instances where students lack access to learning opportunities, the LLs identified further negative consequences for students. One LL commented that students who do not 'fit in' will often suspend their aspirations to learn and merely learn to 'get through' instead (Focus group 2). Another LL commented:

"they almost put it [their learning] on pause and think 'well l'll try to do it on somewhere else' [meaning another placement] where hopefully it will be better" (Focus group 1).

The LLs reported that when students find their access to learning within CLEs restricted they may switch and adopt attitudes of self-preservation, where they end up doing "whatever it takes" to get through (Focus group 2). Another LL commented that: 
"by the time they get to their third year, they've got wise to that...'this is what I need to do to get through these ten weeks' "(Focus group 2).

The LLs spoke of students adopting disengagement strategies to survive their placements which included deploying "fake enthusiasm" (Focus group 2) and those who "just did their time" (Focus group 2). The LLs recognised the detrimental effect that such attitudes had on students' learning:

"that is when learning turns to numbers...'one more week to go', it just turns into 'I'm here to do my forty hours...... counting the days' "(Focus group 2).

However, the LLs also reported that as they become more experienced some students were able to develop more positive capacities for negotiating their placements and opening up access to learning opportunities. For example, one LL reported that:

"By the second or third year... they are able to say, I'm just about to see $X$, can I come back and do that a bit later?' So it gives them that sort of negotiation skills and just that confidence of being able to ... approach their mentors"(Focus group 2).

\section{Discussion}

The LLs perceptions of the challenges student nurses commonly encounter within CLEs reveal important themes regarding power relationships, difficulties surrounding nurses' occupation of mentorship roles and the quality of students' learning 
experiences within the CLE. The nursing literature often focuses on specific and critical aspects of learning in practice, for example considering the importance of mentorship (RCN, 2015; Robinson et al., 2012; Smedley \& Morey, 2009) or belongingness (LevettJones, Lathlean, Maguire and McMillan, 2007; Levett-Jones, Lathlean, Higgins and McMillan, 2009; Levett-Jones and Lathlean, 2009a). Although these aspects deserve attention, in examining them in isolation we risk failing to understand how they are interconnected and arranged around the central challenge of enacting effective mentoring roles and relationships. Learning how to fit in with mentors and to negotiate genuine opportunities for learning, within pressured clinical environments emerged as the key challenge facing students. Although this finding is echoed in the wider literature (Grobecker, 2016; Henderson et al., 2012; Levett-Jones et al., 2007; Levett-Jones \& Lathlean, 2008; Nolan, 1998), this study underlines the significant consequences for students who fail to fit in with the team and access the required learning opportunities.

Our findings demonstrate that students' opportunities to learn in practice are shaped by their position within the power dynamics of the CLE, and in particular students' relationships to their mentors. Mentors have significant power to decide how they treat students within the CLE, and while many mentors discharge their duties admirably, it is evident from this study that some mentors utilise their power in ways that lead to an exploitation of students and a subsequent erosion of their supernumerary status and opportunities to learn. The powerbase for mentors is largely predicated on the students' understanding that mentors are responsible for assessing their competence in practice. The practice assessment document was identified as a key site for the exercising of power. Students know that failed placements can lead to withdrawal from the programme and failure to qualify as a nurse; the assessment format therefore 
underpins the power relationship between mentors and students, creating respective positions of dominance and vulnerability.

In line with the literature, this study demonstrates that vulnerability may lead students towards a number of acquiescent behaviours, including a propensity to conform to poor practice (Levett-Jones and Lathlean, 2009b) and a willingness to undertake nonnursing/worker roles in which opportunities for learning and professional development are limited (Molesworth, 2017; Myall et al., 2008). Students understand that failure to conform to poor practice, especially if this is exhibited by their mentors, may have deleterious consequences for them within the CLE (Levett-Jones and Lathlean, 2009b). Students may feel particularly vulnerable in busy clinical environments, where they are arguably more likely to be exploited as part of the workforce (Webb and Shakespeare, 2008).

Our analysis suggests that we must better protect and promote the learning opportunities of student nurses within practical settings, and that close attention must be paid to the roles, relationships and power dynamics within the CLE. In responding to the extant criticism levelled against the existing mentorship system (e.g. Robinson et al., 2012; Willis, 2012; Willis, 2015), the new NMC Standards (2018) require that mentors are replaced by practice supervisors, supported by designated academic and practice assessors. This is a significant shift, occurring within a relatively short period of time. It is too early to determine the likely impact of the new Standards at this stage, but our research reveals two points that must be considered. 
Firstly, positive relationships between students and mentors are central to enabling learning opportunities within CLEs because the mentors students work with on a daily basis have the most significant influence on their sense of belonging and their subsequent ability to learn (Levett-Jones et al., 2009). Consequeently, when the new NMC Standards are operationalised, it will be incumbent on the practice supervisors to faciliate good relationships, protect learning opportunities and engender students with a sense of belonging. The uncoupling of the supervisor/assessor role may lead to an improved relationship between the students and their practice supervisors, but this benefit should not be taken for granted. The impact of this change will obvioulsy need to be carefully appraised once the changes associated with the new Standards have been embedded.

Secondly, practice supervisors, like mentors, will need to carefully balance their clinical and supervisory roles and responsibilities. Currently mentors report that they struggle to successfully discharge their responsibilities, due to the pressure of their clinical roles (O'Driscoll, Allan and Smith, 2010) and time constraints (Hutchison and Cochrane, 2014; Jokelainen, Jamookeeah, Tossavainen and Turunen, 2011). High workload pressures can restrict mentors' relationships with their mentees (Hurley \& Snowden, 2008; Marks-Maran, 2013; Myall et al., 2008;). A combination of scarce protected mentorship time, significant clinical demands and a lack of placements is unlikely to change and may even worsen, meaning that CLEs are often far from ideal learning environments for students. The Council of Deans of Health (2017) warned that sufficient capacity needs to be built into CLEs (and more broadly into the NHS workforce) to support effective delivery of the new NMC Standards (2018). However, the new Standards allow all registered health and social care professionals to act as 
practice supervisors (with the correct preparation), thereby potentially enabling this responsibility to be redistributed throughout multidisciplinary teams. Such a redistribution will need to be carefully orchestrated and monitored, but if achieved it may make the operationalization of the supervisory role more manageable and lead to improved learning conditions for students within clinical placements. However, there is an inherent risk that without a single point of reference, i.e. a nominated mentor, students may feel lost within the CLE.

\section{Conclusion}

This study has investigated nurse Link Lecturers' perceptions of the challenges facing student nurses in clinical learning environments. Holistic attention to the roles, responsibilities and power dynamics within the CLE has enabled the predicament of student nurses to be better understood. The findings support existing literature in concluding that mentors act as "gatekeepers" to genuine learning opportunities for students and positioned them as key to determining whether students 'fit' into the team, thereby potentially enabling access to genuine learning opportunities. Mentors and students occupy respective positions of domination and vulnerability, and this power relationship must be closely attended to if students' opportunities for learning are to be fully understood. The dynamics of this relationship are founded in the roles and responsibilities mentors have in assessing students in practice and the serious consequences that a negative assessment can have for students. Critically, this study demonstrates that poor relationships with their mentors can have a deleterious impact on students' position within their team and their subsequent opportunities for learning and professional development within the CLE. Our findings highlight that this can lead 
to situations where students feel obliged to undertake non-nursing roles, which limit their learning opportunities, and even to conform to prevailing poor practices. These insights will be significant for clinical staff and academics who will be required to implement the changes embedded in the new NMC Standards (NMC 2018).

\section{References}

Andrews, M., Brewer, M., Buchan, T., Denne, A., Hammond, J., Hardy, G., Jacobs, L., McKenzie, L. and West, S. (2010) Implementation and sustainability of the nursing and midwifery standards for mentoring in the UK. Nurse Education in Practice, 10(5), pp. 251-255.

Bennett, M. and Mcgowan, B. (2014) Assessment matters - mentors need support in their role. British Journal of Nursing, 23(9), pp. 454-8.

Charmaz, K. (2014) Constructing Grounded Theory. London: Sage.

Corbin, J. and Strauss, A. (2008) Basics of Qualitative Research. Techniques and Procedures for Developing Grounded Theory. London: Sage.

Cobin, J. and Strauss, A. (2015) Basics of Qualitative Research. Techniques and Procedures for Developing Grounded Theory. 4th Edition. London: Sage.

Council of Deans of Health (2017) CoDH response to NMC nurse education consultation. https://councilofdeans.org.uk/2017/09/codh-response-to-nmc-nurseeducation-consultation/. Accessed 23.07.2018.

Curtis, J., Bowen, I. and Reid, A. (2007) You have no credibility: nursing students' experiences of horizontal violence. Nurse Education in Practice, 7(3), pp. 156-163.

Grobecker, P. A. (2016) A sense of belonging and perceived stress among baccalaureate nursing students in clinical placements. Nurse Education Today, 36, pp. 178-183.

Henderson, A., Cooke, M., Creedy, D. K. and Walker, R. (2012) Nursing students' perceptions of learning in practice environments: A review. Nurse Education Today 32(3), pp. 299-302.

Hurley, C. and Snowden, S. (2008) Mentoring in times of change. Nursing in Critical Care, 13(5), pp. 269-275.

Hutchison, T. and Cochrane, J. (2014) A phenomenological study into the impact of the sign-off mentor in the acute hospital setting. Nurse Education Today, 34(6), pp. 1029-1033. 
Ion, R., Smith, K., Moir, J. and Nimmo, S. (2016) Accounting for actions and omissions: A discourse analysis of student nurse accounts of responding to instances of poor care. Journal of Advanced Nursing, 72(5), pp. 1054-1064.

Jokelainen, M., Jamookeeah, D., Tossavainen, K. and Turunen, H. (2011) Building organizational capacity for effective mentorship of pre-registration nursing students during placement learning: Finnish and British mentors' conceptions. International Journal of Nursing Practice, 17(5), pp. 509-517.

Levett-Jones, T., Lathlean, J., Maguire, J. and McMillan, M. (2007) Belongingness: A critique of the concept and implications for nursing education. Nurse Education Today, 27(3), pp. 210-218.

Levett-Jones, T. and Lathlean, J. (2008) Belongingness: A prerequisite for nursing students' clinical learning. Nurse Education in Practice, 8(2), pp. 103-111.

Levett-Jones, T., Lathlean, J., Higgins, I. and McMillan, M. (2009) Staff - Student relationships and their impact on nursing students' belongingness and learning. Journal of Advanced Nursing, 65(2), pp. 316-324.

Levett-Jones, T. and Lathlean, J. (2009a) The ascent to competence conceptual framework: An outcome of a study of belongingness. Journal of Clinical Nursing, 18(20), pp. 2870-2879.

Levett-Jones, T. and Lathlean, J. (2009b) 'Don”t rock the boat': Nursing students' experiences of conformity and compliance. Nurse Education Today. 29(3), pp. 342349.

Marks-Maran, D. (2013) Primary Care Nursing/GP Training Pilot Project: Report of the Evaluative Research Study. London.

Molesworth, M. (2017) Nursing Students' First Placement: Peripherality and Marginality Within the Community of Practice. Journal of Nursing Education, 56(1), pp. 31-38.

Myall, M., Levett-Jones, T. and Lathlean, J. (2008) Mentorship in contemporary practice: The experiences of nursing students and practice mentors. Journal of Clinical Nursing, 17(14), pp. 1834-1842.

Nettleton, P. and Bray, L. (2008) Current mentorship schemes might be doing our students a disservice. Nurse Education in Practice, 8(3), pp. 205-212.

Newton, J. M., Billett, S. and Ockerby, C. M. (2009) Journeying through clinical placements - An examination of six student cases. Nurse Education Today, 29(6), pp. 630-634.

Nursing and Midwifery Council (2008) Standards to support learning and assessment in practice. London: NMC. 
Nursing and Midwifery Council (2010) Standards for pre-registration nursing education. London: NMC.

Nursing and Midwifery Council (2018) Realising professionalism: Standards for education and training. London: NMC

Nolan, C. A. (1998) Learning on clinical placement : the experience of six Australian student nurses. Nurse Education Today, 18, pp. 622-629.

O'Driscoll, M. F., Allan, H. T. and Smith, P. A. (2010) Still looking for leadership Who is responsible for student nurses' learning in practice?. Nurse Education Today, 30(3), pp. 212-217.

Pollard, C., Ellis, L., Stringer, E. and Cockayne, D. (2007) Clinical education: A review of the literature. Nurse Education in Practice, 7(5), pp. 315-322.

Randle, J., Stevenson, K. and Grayling, I. (2007) Reducing workplace bullying in healthcare organisations. Nursing standard, 21(22), p. 49-56.

Robinson, S., Cornish, J., Driscoll, C., Knutton, S., Corben, V. and Stevenson, T. (2012) Sustaining and managing the delivery of student nurse mentorship: roles, resources, standards and debates. Report for the NHS London 'Readiness for Work' programme. London.

Royal College of Nursing (2015) RCN Mentorship Project 2015. London: RCN

Smedley, A. and Morey, P. (2009) Improving learning in the clinical nursing environment: Perceptions of senior Australian bachelor of nursing students. Journal of Research in Nursing, 15(1), pp. 75-88.

Thomas, J., Jack, B. A. and Jinks, A. M. (2012) Resilience to care: A systematic review and meta-synthesis of the qualitative literature concerning the experiences of student nurses in adult hospital settings in the UK. Nurse Education Today, 32(6), pp. 657-664.

Veeramah, V. (2012) What are the barriers to good mentoring? Nursing times, 108(39), pp. 12-5.

Webb, C. and Shakespeare, P. (2008) Judgements about mentoring relationships in nurse education. Nurse Education Today, 28(5), pp. 563-571.

Willis P (2015) 'Raising the Bar. Shape of Caring: A Review of the Future Education and Training of Registered Nurses and Care Assistants'. Available online at: https://www.hee.nhs.uk/sites/default/files/documents/2348-Shape-of-caring-reviewFINAL.pdf [Accessed March 2018].

Wilson, J. L. (2016) An exploration of bullying behaviours in nursing: a review of the literature'. British Journal of Nursing, 25(6), pp. 303-306. 